\title{
Children and biobanks: a review of the ethical and legal discussion
}

\section{Kristien Hens, Emmanuelle Lévesque \& Kris Dierickx}

\section{Human Genetics}

ISSN 0340-6717

Volume 130

Number 3

Hum Genet (2011) 130:403-413

DOI 10.1007/s00439-011-1031-8

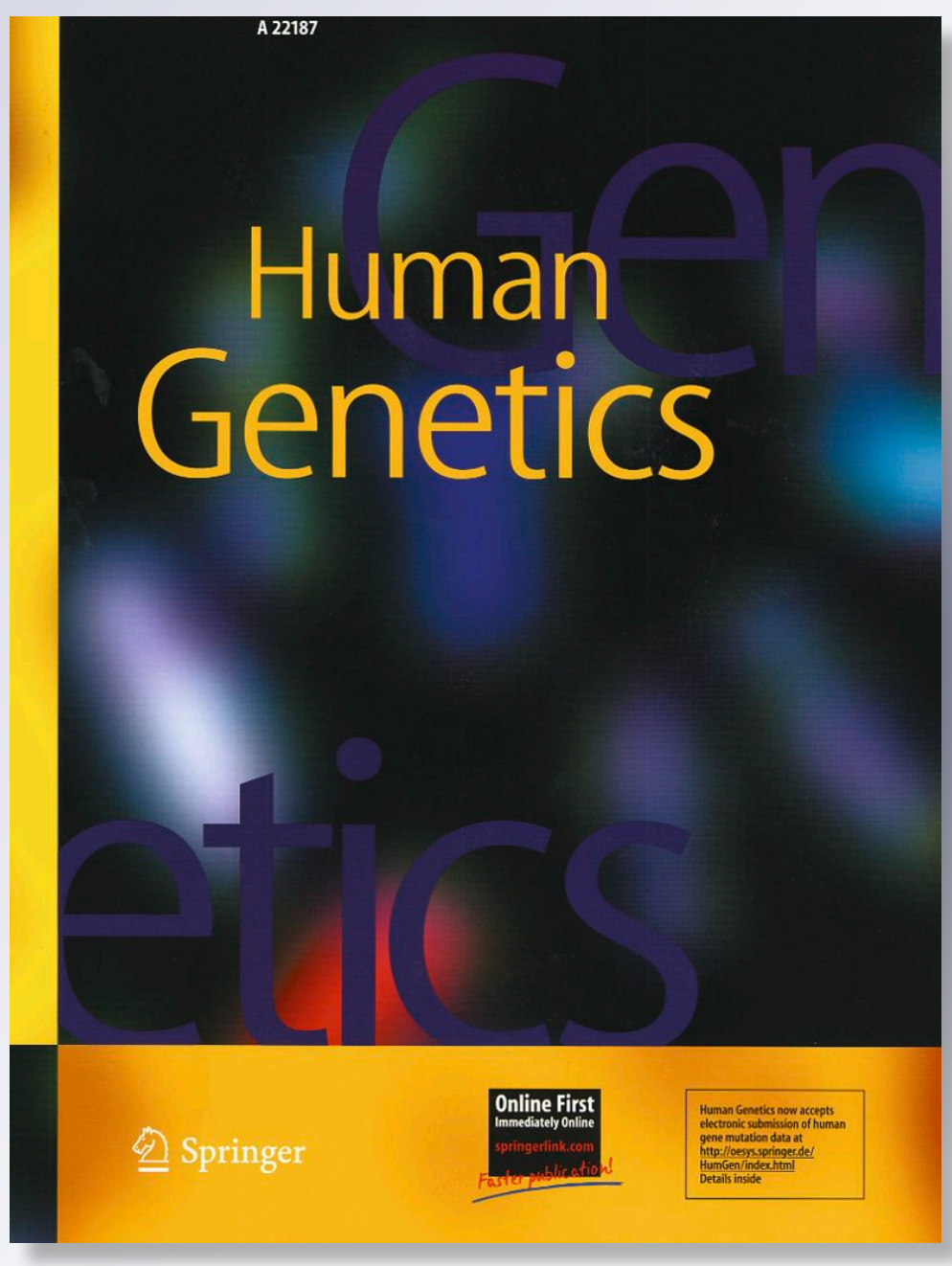

望 Springer 
Your article is protected by copyright and all rights are held exclusively by SpringerVerlag. This e-offprint is for personal use only and shall not be self-archived in electronic repositories. If you wish to self-archive your work, please use the accepted author's version for posting to your own website or your institution's repository. You may further deposit the accepted author's version on a funder's repository at a funder's request, provided it is not made publicly available until 12 months after publication. 


\title{
Children and biobanks: a review of the ethical and legal discussion
}

\author{
Kristien Hens • Emmanuelle Lévesque • Kris Dierickx
}

Received: 10 May 2011 / Accepted: 2 June 2011 / Published online: 10 June 2011

(C) Springer-Verlag 2011

\begin{abstract}
The use of tissue samples from children is vital to genetic research. Collections of such tissue, in so-called biobanks, can take the form of large-scale prospective cohort studies or disease-specific studies using tissue of children with that specific disease. Collections of samples gathered in a diagnostics context, such as blood spot cards, can also be used for genetic research. Research on stored tissue samples from children poses ethical questions that are different from those posed by the use of samples from adults. Also, the ethical questions raised by the participation of children in biobanks are not analogous to those raised by the participation of children in clinical trials. In this review we first give an overview of the international ethical guidelines and legal regulations concerning biobanking and minors. Next, we review the different themes that occur in the ethical literature on this subject. Specifically we focus on questions of risk and benefit, consent and assent and the return of individual results. We also discuss the concept of solidarity, which is a relatively new concept in the context of children and biomedical research. To conclude, we discuss the gaps and questions raised by the review.
\end{abstract}

K. Hens $(\bowtie) \cdot$ K. Dierickx

Centre for Biomedical Ethics and Law,

Katholieke Universiteit Leuven, Box 7001,

Kapucijnenvoer 35/3, 3000 Leuven, Belgium

e-mail: Kristien.Hens@med.kuleuven.be

E. Lévesque

Centre de Génomique et Politiques (CGP),

Département de Génétique Humaine, Faculté de Médecine,

Université McGill, 740, Avenue Dr. Penfield,

Bureau 5202, Montréal, QC H3A 1A4, Canada

\section{Introduction}

Although many biobanks only contain biological material from adults, the use of tissue samples from children is vital to genetic research. Conditions such as allergies, asthma, food intolerances, diabetes and obesity are now commonly attributed to a combination of genetic, phenotypical and lifestyle factors. Large-scale, systematic research using tissue samples and socio-demographical data can shed new light on the development of these conditions.

There are several examples of large cohort studies following children from birth onwards to adulthood. The Avon Longitudinal Study of Parents and Children ('Children of the Nineties') is an example of such study. This study collects detailed phenotypical and lifestyle data from 14,000 children born in 1991-1992 (Pembrey 2004). A similar study is 'Born in Bradford', which examines environmental, psychological and genetic factors that impact the health and development of children perinatally, during childhood and in subsequent adult life. The study also examines factors that influence the health and wellbeing of participants' parents. Recruitment started in March 2007 (Raynor, Born in Bradford Collaborative Group 2008). Other similar studies are Generation R (Rotterdam, approximately 10,000 babies enrolled) and the Norwegian Mother and Child Cohort, which aims to store 380,000 biological samples from pregnant women, their partners and their children for up to 100 years (Jaddoe et al. 2006; Ronningen et al. 2006).

Next to large cohort studies, collections of stored tissue samples from minors can be found with the study of one or some conditions in mind and contain tissue from patients with that disease as well as controls. For example, in the UK there is a 'virtual' tumor bank, which allows for easy sharing of tissue samples from cancer patients within the 
country, including children (Kerr 2003). Another example of research on specific diseases that uses children's tissue is the research of genetic factors of birth defects in the US's National Birth Defects Prevention Study (Jenkins et al. 2008). The Spanish HIV biobank contains tissue samples, including extracted DNA, from HIV infected children and studies the evolution of the disease in children (GarciaMerino et al. 2010). Also, there are many local initiatives in university and teaching hospitals that study the genetic component of specific diseases affecting children. Such studies typically enroll patients or ask participation from parents that seek advice at genetic centers (Hens et al. 2010a).

There is a large collection of existing blood samples from children that has been gathered worldwide. In many countries, newborns are systematically screened for certain diseases through the gathering of heel prick blood. This blood is gathered on Guthrie cards together with some basic information such as place of birth, diet and birth weight. Such collections may potentially be a good resource for genetic epidemiological research and contain de facto material from large populations of children (Klotz et al. 2006). Most of the ethical literature and guidelines in the context of medical research on children have been written with clinical trials in mind. Authors have focused on the risks and burdens such research may pose to children, the issue of parental consent and the potential benefit of participating in a clinical trial to the child in question. There is also substantial existing ethical literature that addresses the storage and use of biological materials from adults for genetic research. Authors discuss the need for consent for the reuse of samples gathered in the clinical context. The debate over whether research participants should be allowed to give broad consent or whether they should be asked to consent to each specific research protocol is still ongoing. Another topic is the issue of privacy; some authors consider participation in biobank research as risky because it could result in the misuse of genetic information by third parties. Another recent line of discussion deals with the return of individual results. Biobank research is primarily fundamental research with no direct benefit for participants. Some argue, however, that participants should be given the option to receive information of potential relevance to their health.

The ethical questions raised by the participation of children in biobanks are not analogous to those raised by the participation of children in clinical trials. As there is often no direct physical intervention, questions of minimal risks are different in the context of biobanks. Also, there is in principle no direct benefit to the child. The issue of consent is a major theme in the ethical discussion about adult participation in research on stored tissue samples. However, when the participants are children, such consent is by defi- nition provided by the parents, making the value of the consent fundamentally different. Also, procedures that may seem not burdensome for adults, such as venepunctures, may be troublesome for children. Also the issue of whether to return individual research results is different when participants are children.

To survey the actual practices in pediatric biobanks, Ries et al. conducted six semi-structured telephone interviews with investigators from the following birth cohort studies: Born in Bradford (BIB3, United Kingdom), Canadian Healthy Infant Longitudinal Study (CHILD, Canada), Copenhagen Prospective Study on Asthma in Childhood (COPSAC, Denmark), Generation R (GenR, Netherlands), Etude Longitudinale Française depuis l'Enfance (ELFE, France) and National Children's Study (NCS, United States). They examined how these studies handled ethical, legal and social issues with regard to recruitment, parental consent and assent/consent from the child, withdrawal, confidentiality and sample/data protection, handling sensitive information and disclosure of results. They found that all studies require initial consent from the mother and paternal consent if the father is available. The breadth of consent varied, but no study asked for complete 'blanket' consent for all possible future studies. As there is frequent contact between investigators and participants in the study there are opportunities to refresh the initial consent and obtain consent for specific activities. The cohort studies would also obtain ethics review for research outside the original scope of the consent. Children are sought to assent, sometimes from as early an age as seven and eight, and would also be asked for full consent in adolescence. The right to withdraw from the study is acknowledged in all six cases, and cohort members could choose not to participate in specific data or sample collection activities. All studies take strong data protection measures in the form of coding and restricted access, and some have special committees to deal with issues such as requests for access by third parties. Interviewees acknowledged that they would report child abuse or other severe harms to social services. Some mention this in the consent forms. General results of studies are published through newsletters. Individual results are returned in some cases, but conditions vary and depend on clinical relevance. One study would not return individual results (Ries et al. 2010).

The issue of minors and biobanks has been given some attention during the past few years. In this paper we shall give an overview of the main arguments, with a focus on the themes of consent, risks, benefits, solidarity and return of results. We shall start with an overview of the themes discussed in international and European guidelines and a review of the theme in legislation. We shall then discuss these themes as they arise in the theoretical and empirical ethical literature. 


\section{Review of guidelines and laws}

This section reviews international ethical guidelines and legal regulations concerning biobanking and children. The analysis is limited to ethical guidelines and legal regulation with dispositions that refer specifically to children or minors. There are few international ethical guidelines and legal regulations that deal specifically with both biobanking and children, so our review includes documents on biomedical research and genetic research. As for our review of legal regulations, we sampled legally binding documents that illustrated local application of core ethical principles.

This section introduces three core elements of international ethical guidelines specific to biobanking research with children: (a) permission from a legal representative, (b) assent and dissent and (c) risks, benefits and necessity.

\section{Permission from a legal representative}

Conventional ethics holds that children do not have the capacity to consent to research because of their limited maturity and comprehension. Children are considered incapable of giving informed consent. International ethical guidelines allow for the possibility of substituting permission from a legal representative for a child's consent. Because the legal representative does not act on behalf of him or herself, but does so in place of the child, it is more appropriate to talk of "permission" or "authorization" to participate rather than "consent".

The Helsinki Declaration states that authorization must be sought from the legally authorized representative when the research participant is incompetent (WMA 2008). According to guidelines of the Council for International Organizations of Medical Sciences (CIOMS), a parent or a legal representative must give permission before research is undertaken with a child (CIOMS 2002, 2008). The International Declaration on Human Genetic Data and the guidelines developed by the Organisation for Economic Cooperation and Development (OECD) specify that the authorization should be obtained from a legal representative in accordance with domestic law (UNESCO 2003; OECD 2009).

The ethical principle of obtaining permission from a legal representative is also discussed in texts having legal authority. The Convention on Human Rights and Biomedicine and its Additional Protocol on Biomedical Research stipulate that research may be carried out with a person who does not have the capacity to consent with the authorization of his/her representative or an authority, person or body provided by law (CE 1997, 2005). France's Code of Public Health specifies that biomedical research with children must be authorized by persons having parental authority (France's Code of Public Health 2004). The Civil Code of
Québec stipulates that participation of children is subject to authorization by a person having parental authority or otherwise qualified as legal representative (CCQ 1991).

Assent and dissent

Although children do not have the capacity to consent to research, their developing maturity and comprehension can be recognized by other mechanisms. Many international ethical guidelines require that a child's opinion and preferences about participation in research be considered in addition to permission from legal representative. These mechanisms that offer children the possibility to express themselves are generally grouped into two concepts: assent and dissent.

Assent is the requirement that children demonstrate their agreement to participate in research. Obtaining assent from a child involves prior communication to him or her of at least some of the pertinent and essential information about the research. Many international ethical guidelines recognize that a child's assent must be obtained depending of the child's capabilities.

Guidelines use distinct wording to capture this gradation of capability. A child's opinion should be considered "to the extent of the [child's] capabilities" (CIOMS 2002, 2008), "as an increasingly determining factor in proportion to age and degree of maturity" (UNESCO 2003) and when he/she is "able to give assent to decisions about participation in research" (WMA 2008). Guidelines from OECD request adoption of a "clearly articulated policy on whether, when and how the minor's assent will be obtained" (OECD 2009).

Dissent may be considered the opposite of assent. By dissenting, children indicate their refusal to participate. Although obtaining dissent of children does not necessitate the communication of all the information about the research, it requires at least that they understand the research to a certain extent. Again, guidelines employ various wordings to stipulate the respect of the dissent of children. It could be referred to as the "subject's dissent" (WMA 2008) or "child's refusal to participate" (CIOMS 2002, 2008; WHO 2003). Some guidelines mention that dissent could be overruled in some circumstances when a therapeutic benefit is expected (CIOMS 2002, 2008), but biobanking is considered non-therapeutic research.

The ethical principle of respect for children's assent and dissent usually finds application in legally binding regulation. Researchers in jurisdictions subjected to the Convention on Human Rights and Biomedicine and its Additional Protocol on Biomedical have to take into consideration the opinion of the minor in proportion of her/his age and maturity and to assure that the minor did not object to research (CE 1997, 2005). Québec legislation gives effect to a 
child's objection when "he understands the nature and consequences of the experiment" (CCQ 1991). In France, a child's right to assent is fully recognized by obligations to give him/her information adjusted to their capacity of understanding and to try to obtain his/her agreement (France's Code of Public Health 2004). In all cases, a child's refusal must be respected (France's Code of Public Health 2004).

Childhood incapacity is temporary. Children continue to grow up and mature after their initial inclusion in a biobank. Considering that biobanks can store samples for decades, standards of assent and consent need to take into account an aging subject. CIOMS guidelines mention that consent of children to continue participation should be obtained when they become capable of giving informed consent (CIOMS 2002). Guidelines from OECD mention the importance for biobanks to have a policy "once such participants become legally competent to consent" (OECD 2009).

\section{Risks, benefits and necessity}

Due to the fact that children are considered vulnerable and warrant protection, the intensity of the expected risks and benefits are subject to specific requirements. These requirements operate as safeguards that prevent inappropriate decision making by legal representatives that may harm individuals of a vulnerable group. Collection and storing of samples for biobanking is usually considered non-therapeutic research because it does not aim to procure direct benefit to participants. In the context of non-therapeutic research involving children, the authority of the legal representative is usually limited by three factors: (1) the degree of risk the research poses, (2) the prospect of benefit for similar individuals and (3) the necessity to include children in the research.

The first factor requires that research does not entail more than a minimal degree of risk for children. International ethical guidelines refer to "minimal risk" (WMA 2008; CIOMS 2008), or risk "no more likely and not greater than the risk attached to routine medical or psychological examination" (CIOMS 2002). The second factor seeks to ensure that although no direct benefit is intended, indirect benefits are expected for a group of persons similar to the children participating in the research. Both the kind of benefit and the similarity of the group required vary among international ethical guidelines. It could be suggested that research should strictly seek "to obtain knowledge relevant to the health needs of children" (CIOMS 2002, 2008). Child participants could represent a broad class of persons (WHO 2003) or a population (WMA 2008). Thus, benefits might be expected for persons with the same condition, disease or handicap as the children. The third and last factor holds that inclusion of children must be necessary to achieving the aim of the research with adults. Inclusion of children is justified when the research "cannot instead be performed with competent persons" (WMA 2008) or "might not equally well be carried out with adults" (CIOMS 2002, 2008).

The three conditions for the participation of children discussed above receive similar consideration by supranational and national law. European regulation under analysis fully applies the three conditions (CE 1997). Québec's legislation strictly refers to only two of these principles: experiment may be undertaken with minors when it involves less than serious risk to health and when it has the potential to produce results capable of conferring benefit to other persons in the same age category or having the same disease or handicap (CCQ 1991). In France, biomedical research without direct benefit to children is subjected to application of all three ethical conditions (France's Code of Public Health 2004).

\section{Review of the specific themes (empirical/theoretical literature)}

In this section, we will review the current ethical literature on the participation of children in biobank research. We review both the theoretical and empirical literature.

\section{Consent}

Perhaps the most widely discussed issue with regard to pediatric biobanks is the issue of consent. One major difference between the use of stored tissue samples from adults and from children is the fact that the latter typically do not give consent themselves. This is thought to be a major ethical difference. Questions raised are for example who should consent, the right of a child to assent or dissent to biobank research and the scope of parental consent. The scope of parental consent has, according to Hens et al. two dimensions: one temporal and one related to content. The first dimension relates to the question of whether parents have the right to consent to the storage and use of pediatric material until an unspecified time or whether children need to be recontacted when they reach the age of competence. The second dimension has to do with the question of whether parents have the right to consent to future unspecified research on the stored tissue samples of their children (socalled broad consent) under certain conditions (i.e. ethics review) or only to specific types of research (Hens et al. 2011a).

With regard to the question of who should consent to research on stored tissue samples from children, the literature and the guidelines are fairly unanimous. The fact that 
parents or legal guardians can and should consent is not questioned (Burke and Diekema 2006; Fisher 2006; Helgesson 2005; Knoppers et al. 2002). Holm justifies this by stating that biobank storage and research on pediatric samples does not have demonstrable negative effects on children. Also empirical research suggests that parents and children do not seem to question the parental rights to consent. For example, in a focus group study by Hens et al. participants stated that it is a fact of life that parents make decisions for their children, and it was believed that they did so in good faith. As biobank research is mostly genetic research, and genetic information is shared between parents, one could argue that consent for research should be given by both parents. However, as many children do not live with both (biological) parents, this may be practically unfeasible. Therefore, it is suggested that consent by two parents should be seen as a best practice rather than an absolute requirement (Hens et al. 2009a).

Although the need for and the validity of parental consent is not questioned, authors also do not question the right of a child to give his or her own opinion on the matter. As soon as a child is capable of expressing his or her opinion on the matter, he or she should be given the opportunity to do so (Goodenough et al. 2004; Helgesson 2005; Hens et al. 2009a; Holm 2005; Knoppers et al. 2002). In this respect, Helgesson states that parents can help children to become autonomous persons by giving them the capacity to exercise their autonomy in the degree they are capable of. There is, however, uncertainty about the age around which children can make such decisions.

Goodenough et al. mention the age of $9-11$ as the age where children are gradually starting to make choices for themselves. However, in a focus group study by Hens et al. it was found that teenagers often quoted higher age thresholds, around 16 years of age (Hens et al. 2011d). And in a survey of professionals by the same authors, that age range was quoted as well (Hens et al. 2010b). However, empirical data from Williamson et al. show that children enrolled in a longitudinal cohort study thought of consent as an ongoing process in relation between themselves and their parents. They also believed they would gradually receive more control as they grow older. In the same study, however, it was found that children sometimes felt that they did not have an option to dissent or not to participate with certain activities. Indeed, the question in how far children should be given the right to dissent to certain procedures their parents consented to is still an issue of ongoing debate. In a study of interviews of professionals by Hens and Dierickx it was found that many interviewees would not force a screaming child to undergo certain procedures and would give priority to the dissent of a child. However, one interviewee thought that parents should be the ones to decide whether to continue with a procedure or not. Participating in research may be considered as an example of a normal activity that children just have to do, despite their wishes (Hens and Dierickx 2010). Garrath Williams argues in this respect that there is a lesson to learn here for the participating children: cooperation with others, of which he thinks medical research is an example, means putting up with things you dislike. Therefore, he believes that a child's dissent is not overriding if what is asked from them is reasonable (Williams 2011).

What is the scope of parental consent? In a temporal sense, can parents consent to research on the tissue samples of their children ad aeternam or should the young adult be asked to give renewed consent once he or she reaches the age of competence. What's more, should a young adult be given the opportunity to opt out of participating in biobank research? There is some agreement in the ethical literature that children should be able to renew their consent when they reach the age of competence. Burke and Diekema are in favor of such reconsent for two reasons: first, it allows minors to participate more as they grow older and to give full consent when they reach adulthood. Second, the initial consent was not obtained from the participant and therefore has limited temporal scope (Burke and Diekema 2006). Helgesson and Fisher follow this line of argument, stating that proxy consent and full informed consent are fundamentally different because proxy consent does not express the autonomy of the participant (Fisher 2006; Helgesson 2005). Along the same lines, Holm argues that children should be given the opportunity to withdraw their samples and data from the study. He believes the right to withdraw is more important for children than adults because they have never autonomously consented (Holm 2005). A study in the US using telephone interviews by Goldenberg et al. investigates the need for recontacting people for reconsent when they reach adulthood. They performed telephone interviews with 1,186 patients from 5 academic medical centers by using a hypothetical scenario. They found that a majority $(67 \%)$ would not be concerned about the use of their sample/data after they reached adulthood. Those respondents who were concerned were more likely to be more private about their medical records, less trusting of medical researchers, or African-American. $46 \%$ believed consent should be obtained to continue using their sample and data for research. A minority of $26 \%$ would not want researchers to use their sample or data if they could not be located to ask for consent. These findings support the idea that it is ' $\mathrm{good}$ practice' to obtain consent when donors reach adulthood, but that it is acceptable to continue to conduct research when adults cannot be located (Goldenberg et al. 2009).

Another aspect of the scope of parental consent is the type of research for which parents are giving consent. In the general discussion on consent and biobanks, this corresponds to the question of whether participants can be asked 
to give broad consent to any future research that is done on their samples under certain conditions or whether they should only be allowed to consent to well-circumscribed specific research and be contacted when research protocols change. In ethical literature there is no consensus about this, although actual biobank practices seem to favor broad consent. Hens et al. have argued that the issue is further complicated when participants are children and consent is given by the parents. Although they accept that parents can consent to the storage and use of samples from children for research, they state that this should not be broad consent. They base their statement on two ideas. The first idea is that children are allowed to develop and express their own values as they grow older and the second is that science and research are not completely value-free. Therefore, children should be allowed to express their opinions on the type of research that is performed on their samples as they grow older. They suggest that parents can give consent for further unspecified research if such research aims to understand and treat diseases, but that if samples are used later on for research that is more sensitive, such as behavioral research or IQ-related research, participants should be recontacted for renewed consent (Hens et al. 2011a).

The scope of parental consent has been given some attention with the publication of a theoretical-ethical policy forum in Science by Gurwitz et al. (2009a, b). They refer to the specific vulnerability of children to limit the scope of parental consent. This vulnerability is temporary: most children will become competent adults one day. However, a DNA sample donated by his or her parents can still be used decades later. Given the advent of new techniques such as rapid sequencing of entire genomes, a donor's privacy can never be completely guaranteed. They suggest that children should be recontacted when they reach the age of consent to allow continuing research to be done on their samples and data. Moreover, they suggest that when research on pediatric data is done, this should be done in-house and such data should never be shared with researchers outside of the original institution until the minor is capable of giving full informed consent. In response, authors have argued that such approach would delay research and that good biobank governance, including stringent privacy protection policies and ethics committee oversight, minimize threats to privacy (Brothers and Clayton 2009; Hens et al. 2009b). However, Gurwitz et al. have responded that this need not be the case as their suggestions include in-house genotyping of children's DNA samples (which may include outsourcing in lieu of local facilities) for retaining control over spread of information and material, which would assure that research will not be substantially delayed. They also suggest that mature minors may reach a level of autonomy sufficient for consent on inclusion in biobanking projects before the age of legal adulthood (Gurwitz et al. 2009b).
Solidarity

The use of stored tissue samples is fundamentally different from traditional medical research in that it does not entail direct interventions on the participants other than venepunctures or mouth swabs. Therefore, many authors think that focusing too much on the right to consent and the autonomy principle in this context can no longer be justified. Biobanks have the right to appeal to people to participate in such research, especially when the aim is to understand and aid severe conditions (Chadwick and Berg 2001; Hoedemaekers et al. 2006; Hoedemaekers et al. 2007). In this respect, the principle of solidarity is quoted as an alternative to traditional autonomy-centered bioethics. However, Hens et al. have argued that even the advocates of the solidarity principle make an exception for children (Harris 2005; Hens et al. 2011b). Children are in everyday life exempt from certain duties that adults have, although certain civilized and solidary behavior is expected from them. But the extent to which the inclusion of samples for biomedical research should be considered part of the duties children is not clear.

In a paper on a child's obligations in this respect, Barry Lyons argues that as beneficence cannot be used to defend the enrolment of children in non-therapeutic research, some seek to justify this enrolment with a model of obligations. Children would be obliged to participate because they themselves potentially benefit or other children would benefit. Lyons does not agree with this: in his view competent adults are offered more protection than children, as they consented themselves to the research. In most ethical models, being under an obligation means still being offered the choice to participate and being allowed to refuse. However, children, participating in a regime of parental consent, do not have this option and are hence forced to participate. The obligation model is ill suited as a model to advocate children's participation in research (Lyons 2011).

Garrath Williams has a different viewpoint and sees the participation of children in research as a means for these children to learn how to cooperate very early in life. He argues that consent should not be our principal concern when children are involved in research. Advocates of the autonomy doctrine state that consent is needed because otherwise researchers treat participants merely as means to their own ends. Williams argues that Kant also stresses the (imperfect) duties people have to one another. Everyone is duty-bound to contribute to social goods in some way. Children should also learn that they have these duties. He also believes that in this respect, tenderness towards children's possible discomfort is exaggerated, because cooperation means also putting up with things you do not like. Children's readiness to cooperate should not be undermined by overstressing the autonomy principle (Williams 2011). 
Hens et al. advocate a model of limited solidarity for children. Children can be asked to enroll in biobank research, as some of this research just cannot be done with adult participants. However, children should also be given more protection than adults in research. Because they are vulnerable persons, they should be shielded from too risky or burdensome procedures (Hens et al. 2011b).

\section{Risks and burdens}

A principle from non-therapeutic research on children is that such research should entail no more than minimal risk to participants (Helgesson 2005; Holm 2005; Knoppers et al. 2002). This principle is also quoted in the context of biobanks. However, potential risks related to participation in biobank research are different from risks related to, for example, clinical trials with children. An empirical study by Neidich et al. (2008) has shown that most women interviewed considered enrollment in a biobank as entailing no more than minimal harm.

The types of risks associated with the use of stored tissue samples for genetic research can be divided into three categories: risks of physical and emotional burden, risks related to genetic information (privacy risks) and risks of breaching the values of the child (Helgesson 2005; Hens et al. 2011b).

In qualitative empirical studies, the fear that participation in genetic research may burden children, physically and emotionally, is often expressed. Children may experience fear of needles and the clinical environment or enrollment in research may take too much of their time (Goodenough et al. 2004; Hens et al. 2011d; Kaufman et al. 2008). A quantitative study by Berrington et al. (2010) found that $60 \%$ of the parents that refused the participation of their newborns in a research study attributed their declining interest to the need for venepunctures with children, although those that did participate did not view venepunctures as problematic. Hens et al. attribute the emphasis that is put on the reduction of burden in the case of children to the fact that they are more vulnerable than adults, as they have a limited autonomy and are less able to understand the procedures. As it is difficult to assess whether a burden is acceptable or not they advocate in favor of the precautionary principle and in favor of putting the burden threshold rather low. This can be done by using non-invasive techniques such as oral fluids or anesthetic creams. Even better still would be to reuse existing samples and data, such as the use of blood spot cards for DNA analysis collected at birth from newborns (Hens et al. 2011b).

Biobank research presents the risk of a possible breach of confidentiality. Access to genetic information could lead to discrimination of the participants or to personal stigma (Burke and Diekema 2006; Holm 2005). The latter is related to the fact that participation in research about a given disease may lead to the participant being associated with the disease. In the policy forum mentioned earlier, Gurwitz et al. state that the privacy risks associated with the use of samples from children for genetic research are so high that if such samples are used, they should not be shared with other research institutions until the minor has had the opportunity to consent. As a consequence, each institute analyzing children's DNA for research should invest in in-house processing facilities (Gurwitz et al. 2009a, b). On the other hand, this could stall research and demand high investment (Brothers and Clayton 2009). Hens et al. have argued in this respect that the reasonable prevention of risk should precede consent, both in the case of adults and in the case of minor participants. They think risks related to genetic privacy should be solved on two levels: first, in society in general (through just institutions and genetic privacy laws) and second, on the level of biobank governance, by means of appropriate data protection policies of biobanks, especially when samples are shared (Hens et al. 2011b).

A third risk associated with genetic research on stored tissue samples from children arises from the fact that samples can be stored in tissue sample collections over a longer period and new types of research can be carried out on them. Small children have limited autonomy and hence the burden of decision making lies with their parents. However, they gradually develop and revise their own value schemes, and their values may not correspond to the values of their parents with regard to the types of research done on their samples. In the section on consent it was mentioned that it is accepted that parents make decisions for their small children when these are still small. However, it is also generally accepted that children are given the opportunity to autonomously decide on what happens to them as they grow older (Goodenough et al. 2004; Williamson et al. 2004). Hens et al. think that it is important in this respect that a child, when he or she grows older and gradually develops his or her own value scheme, is consulted and made aware of proposed research, especially if this research is far removed from its original objectives. They maintain that an ethics committee can decide whether a new type of research is sufficiently covered by the original consent (Hens et al. 2011b).

\section{Benefit}

In the context of general medical research on children, it is often stated that such research must benefit the participant. Although this is probably a valid principle for clinical trials, it is more difficult to apply to (non-therapeutic) biobank research. Although some think that there may be some benefits to individuals from the general assessment done in the 
context of biobank research (Kaufman et al. 2008), or if individual research results are returned to participants (Hens et al. 2011c), this principle is only marginally applicable because many children may never experience any health benefit from participating.

Another principle quoted in this respect is the fact that research on children should at least benefit children in general or children with the same disease. Indeed, a majority of respondents of a survey of parents of children with cancer would consent to research on tissue samples of their children, including genetic research, but would prefer research for pediatric conditions. Just over a half (54\%) wished to renew consent if stored tissue is used for another purpose (McMurter et al. 2011).

However, this principle is questioned by some authors. Holm points out that the argument behind group benefit is that even if there is no direct benefit to the participant, he or she benefits indirectly through the group benefit. However, this is not applicable to children as group membership is not stable. The disease could only afflict a certain age group, a condition could be rapidly proceeding, or research could be spread over a long period of time, which is often the case with biobank research (Holm 2005). Hens et al. argue that the requirement of group benefits is further complicated in the case of fundamental research, as it is hard to pin down exactly what the immediate benefits will be for children that suffer from a genetic disease during fundamental research. Therefore, they doubt that the requirement of group benefit can be easily transferred from clinical trials to genetic biobank research. They argue therefore that a third type of restriction, the one that states that 'research can be done on children if it cannot be done on adults' is a more straightforward one (Hens et al. 2011b). This is analogous with what Barry Lyons calls the consequentialist reason for children's participation in medical research. Unless some research is carried out on children, there will be little progress in pediatric research (Lyons 2011).

\section{Return of individual results}

The issue of whether biobanks should return individual results that may or may not be of health relevance to adult participants has been amply discussed in the biobank literature. When participants are minors, some specific questions arise: should parents be allowed to decide not to receive vital information about their children? Should they have the right to access all details about their children's genetic makeup? Is there a duty to receive results that could affect the health of the child during childhood? Do researchers have a more stringent duty to return individual results when their research subjects are children (Hens et al. 2009a)? In an article dedicated to the question of returning results in pediatric research, Hens et al. have identified two important dimensions: the autonomy of the participant and the duty of the researcher. In the general discussion on returning individual research results, the autonomy principle and the right of participants to decide whether they want to receive certain information about their health are often quoted as arguments. However, these principles cannot be directly applied in the case of pediatric biobanks because the persons making the choices are not the participants themselves. The authors argue that the right not to know does not apply to parents with regard to information about early onset treatable or preventable diseases because in the case of children the best interest principles overrides parental autonomy. They also believe that, in analogy with literature on genetic screening and testing of children, parents should not have access to each and every piece of information about their child that would result from genetic research. With regard to the question of whether researchers have a more stringent duty to return individual information when their research subjects are children, they answer positively, given that there is an appropriate infrastructure to return such information. They base their assertion on the fact that children are a vulnerable group that, unlike adults, cannot provide for their own health care. Therefore, researchers have a higher ancillary care duty toward children than toward adults and should seriously consider returning information about early onset treatable and preventable diseases (Hens et al. 2011c).

\section{Discussion}

Our review of the international ethical guidelines and legal regulations governing biobanking and children addressed three core elements: (1) permission from a legal representative, (2) assent and dissent and (3) evaluation of risks, benefits and necessity. Each of these requirements is recognized by international ethical guidelines as an essential basis for any biobanking project with children. These requirements can establish a basis for research with children that do not have direct benefit for them. But the issue of the applicability of additional ethical rules especially designed for research with samples remains. In fact, one of the particularities of biobanking is that it may involve storage and analysis of samples without any direct interaction with the sample donor (e.g., residual samples from clinical use or from a study).

Ethical rules developed for research with samples sometimes permit exceptions to general principles (Helgesson et al. 2007; Lévesque et al. 2009). For instance, the Helsinki Declaration recognizes that storage and analysis of human material may be done without consent when it would be impossible to obtain or when it would pose a threat to the validity of the research (WMA 2008). Another exception is 
that research with deidentified samples can be exempted from the usual risk-benefit evaluation by a research ethics board. The US Common Rule includes this exception (US Federal Register, 45 C.F.R., part 46). The waiver of consent could interfere with parental authorization/assent/dissent, and the absence of risk-benefit evaluation could jeopardize the three criteria evaluation (minimal risk, benefit, necessity). In the guidelines these exceptions are not formulated especially for research with children. Application of exceptions to research with children-which is itself a sort of exception-cannot be done automatically and may be controversial (for an illustration about the Common Rule, see Brothers 2011 and Rothstein 2010). As demonstrated above, there is more discussion about the use of samples from children in the literature than in the guidelines.

Discussions of consent are prominent in the ethical literature on children and biobanks. Consent is fundamentally different in the case of minor participants as it is the parents who consent to the inclusion of their children in the biobank. Authors agree that consent by a parent is valid, although limited in temporal scope and in content. Young adults should have the opportunity to withdraw samples or to disagree to participate in certain types of research. Also, the fact that children should be given the opportunity to assent seems generally accepted. The age at which a child or young adult can fully understand genetic research and make an informed decision is still unsure. Age ranges quoted are between 7 and 16, although some would prefer to make a decision on the basis of maturity rather than by a fixed age threshold (Ashcroft et al. 2003). More empirical research is probably needed to get a firm view on how to assess maturity in this respect. Although in principle the right to dissent is not questioned, there is disagreement on the weight one should give a child's dissent. Can a child be forced to undergo a venepuncture for the sake of research? Related to this, one could ask whether a child with a rare genetic disease, with 'precious' DNA, would be more obliged to share it than a child who is part of a large birth cohort study.

In principle, children have the right to have a say in matters that concern them, a right that is also laid down in the Convention on the Rights of the Child (1989). This would mean that if research is done on samples outside of the original objectives, children would need to be recontacted and asked to express their opinion. Such recontact would also become more important as the child grows older and develops his or her value scheme. However, in the case of adult biobanks, participants are often asked one-time broad consent subject to certain conditions. One could argue also that the need for medical research to proceed is higher than the need to respect a child's growing autonomy. Recontacting may not be too burdensome in longitudinal biobanks when the broad consent foresees recontact for updates. The same level of burden may not hold true for other biobanks. Further thought needs to be given to weighing these considerations against each other. However, given the speed of current technological advances it may become easier to notify participants of new research that may be done on their samples through text messages or emails.

A major disagreement amongst authors circles around the role of consent. In one view, its primary function is the acceptance of certain risks. Because children cannot consent, they should not be subjected to the potential privacy risks of participating in genetic research that involves samples sharing. From this perspective, privacy can only be guaranteed through gathering, extracting and researching samples at the same location. Others envisage a separation of consent and privacy risks. They view the actual role of consent as a means of assessing one's values with regard to research practices rather than a conscious acknowledgement of risks. In this view, the privacy issue should be solved on a governmental and even societal level, through just laws and adequate data protection. This latter may be too big an assumption for some. A given society or country may have a public health system where insurance companies have limited power, but they may not enforce the same level of genetic privacy as other countries. Samples are also stored over a long period of time while a society evolves towards a completely different system. Also, the texts analyzed assume a model of child/parent relationship that is relevant in Western countries. This may however, not be easily transferrable to other countries.

The principle of solidarity is relatively new in biomedical ethics. Although it is regarded by some as an extra principle next to autonomy, beneficence, non-maleficence and justice, its scope and modalities require further development. It is difficult to lay down exactly what is meant by a duty to participate in medical research, especially when trading it off against the right to autonomy. Especially in situations that do not completely conform to the typical case of adult participants, such as cases with minor participants, there is need for further reflection.

The requirement that children should not be burdened with research seems to move the pendulum in favor of reusing diagnostic samples for research, perhaps in combination with medical data gathered by the public health system. However, this may not seem completely in line with the requirement that children be actively involved in decisions about research on their samples (Hens et al. 2010a). Equilibrium between these concerns must be found.

We have not discussed the issues of ownership and commercialization. These issues are covered extensively in the literature on adult biobanks but there may be some differences when children are concerned. For an ownership example, placental blood may contain genetic information on the mother and the child (Holm 2005). Who is then the 
rightful owner of the information? What if research on a rare gene variant found in a child results in a major commercial success? Who should be paid (if at all)?

Our discussion dealt with the issue of traditional biobanks that store biological materials such as DNA samples. Distinct ethical issues may arise for biobanks that store the data results from a partial or full genome scan. We stated that the use of stored tissue samples from minors in genetic biobank research is a step away from the clinical trial paradigm, although some of its ethical concepts are still applicable. However, this shall become less so when databases will become more virtualized and contain more data and materials. In this respect, questions about who needs to have a say on the different steps of sequencing, analysis and storage will need to be answered.

Acknowledgments Kristien Hens and Kris Dierickx were supported by FWO Flanders, project number G029107. They also gratefully acknowledge the financial support of the European Commission under the DISC REGENERATION project (NMP3-LA-2008-213904). Emmanuelle Lévesque gratefully acknowledges the financial support of the Québec Network of Applied Genetic Medicine (RMGA) and the Canadian Institutes of Health Research (Écogène project).

\section{References}

(1989) United Nations Convention on the Rights of the Child Ashcroft R, Goodenough T, Williamson E, Kent J (2003) Children's consent to research participation: social context and personal experience in validate fixed cutoff rules. Am J Bioeth 3:16-18

Berrington JE, Snowdon C, Fenton AC (2010) Parents' attitudes to neonatal research involving venepuncture. Clin Ethics 5:148-155

Brothers KB (2011) Biobanking in pediatrics: the human nonsubjects approach. Per Med 8(1):71-79

Brothers KB, Clayton EW (2009) Biobanks: too long to wait for consent. Science 326:798

Burke W, Diekema DS (2006) Ethical issues arising from the participation of children in genetic research. J Pediatr 149:34-38

Chadwick R, Berg K (2001) Solidarity and equity: new ethical frameworks for genetic databases. Nat Rev Genet 2:318-321

Civil Code of Québec (CCQ) (1991), S.Q., 1991, c. 64, Province of Québec

Code de la santé publique (France's Code of Public Health), modified by Law n'2004-806 (9, August, 2004)

Council for International Organizations of Medical Sciences (CIOMS) (2002) International ethical guidelines for biomedical research involving human subjects, Geneva

Council for International Organizations of Medical Sciences (CIOMS) (2008) International ethical guidelines for epidemiological studies, Geneva

Council of Europe (CE) (1997) Convention for the protection of human rights and dignity of the human being with regard to the application of biology and medicine: Convention on human rights and biomedicine, Oviedo

Council of Europe (CE) (2005) Additional protocol to the Convention on human rights and biomedicine, concerning biomedical research, Strasbourg

Fisher CB (2006) Privacy and ethics in pediatric environmental health research-part II: protecting families and communities. Environ Health Perspect 114:1622-1625
Garcia-Merino I, de Las CN, Jimenez JL, Garcia A, Gallego J, Gomez C, Garcia D, Munoz-Fernandez MA (2010) Pediatric HIV BioBank: a new role of the Spanish HIV BioBank in pediatric HIV research. AIDS Res Hum Retroviruses 26:241-244

Goldenberg AJ, Hull SC, Botkin JR, Wilfond BS (2009) Pediatric biobanks: approaching informed consent for continuing research after children grow up. J Pediatr 155:578-583

Goodenough T, Williamson E, Kent J, Ashcroft R (2004) Ethical protection in research: including children in the debate. In: Smyth M, Williamson E (eds) Researchers and their 'subjects'. The Policy Press, Bristol, pp 55-72

Gurwitz D, Fortier I, Lunshof JE, Knoppers BM (2009a) Research ethics. Children and population biobanks. Science 325:818-819

Gurwitz D, Fortier I, Lunshof JE, Knoppers BM (2009b) Research ethics children and population biobanks response to comments. Science 326:799

Harris J (2005) Scientific research is a moral duty. J Med Ethics $31: 242-248$

Helgesson G (2005) Children, longitudinal studies, and informed consent. Medicine. Health Care Philos 8:307

Helgesson G, Dillner J, Carlson J, Bartram CR, Hansson MG (2007) Ethical framework for previously collected biobank samples. Nat Biotechnol 25(9):973-976

Hens K, Dierickx K (2010) The use of stored tissue samples from minors for genetic research. Interviews with professionals. New Genet Soc 29:1-14

Hens K, Nys H, Cassiman JJ, Dierickx K (2009a) Genetic research on stored tissue samples from minors: a systematic review of the ethical literature. Am J Med Genet A 149A:2346-2358

Hens K, Wright J, Dierickx K (2009b) Biobanks: oversight offers protection. Science 326:798-799

Hens K, Nys H, Cassiman JJ, Dierickx K (2010a) The use of diagnostic collections of DNA for research: interviews at the eight Belgian centers for human genetics. Eur J Med Genet 53:274-279

Hens K, Snoeck J, Nys H, Cassiman JJ, Dierickx K (2010b) An exploratory survey of professionals on the use of stored tissue samples from minors for genetic research. Genet Mol Res 9:973-980

Hens K, Nys H, Cassiman JJ, Dierickx K (2011a) Children, biobanks and the scope of parental consent. Eur $\mathrm{J}$ Human Genet doi:10.1038/ejhg.2011.29

Hens K, Nys H, Cassiman JJ, Dierickx K (2011b) The return of individual research findings in paediatric genetic research. J Med Ethics 37:179-183

Hens K, Nys H, Cassiman JJ, Dierickx K (2011c) Risks, benefits, solidarity: a framework for the participation of children in Genetic Biobank Research. J Pediatr doi:10.1016/j.jpeds.2010.12.036

Hens K, Nys H, Cassiman JJ, Dierickx K (2011d) The storage and use of biological tissue samples from minors for research: a focus group study. Public Health Genomics 14:68-76

Hoedemaekers R, Gordijn B, Pijnenburg M (2006) Does an appeal to the common good justify individual sacrifices for genomic research? Theor Med Bioeth 27:415-431

Hoedemaekers R, Gordijn B, Pijnenburg M (2007) Solidarity and justice as guiding principles in genomic research. Bioethics 21: $342-350$

Holm S (2005) Informed consent and the bio-banking of material from children. Genomics Soc Policy 1:16-26

Jaddoe VW, Mackenbach JP, Moll HA, Steegers EA, Tiemeier H, Verhulst FC, Witteman JC, Hofman A (2006) The generation R study: design and cohort profile. Eur J Epidemiol 21:475-484

Jenkins MM, Rasmussen SA, Moore CA, Honein MA (2008) Ethical issues raised by incorporation of genetics into the National Birth Defects Prevention Study. Am J Med Genet C Semin Med Genet 148C:40-46

Kaufman D, Geller G, LeRoy L, Murphy J, Scott J, Hudson K (2008) Ethical implications of including children in a large biobank for 
genetic-epidemiologic research: a qualitative study of public opinion. Am J Med Genet, Part C Seminars in Medical Genetics $148 \mathrm{C}: 31-39$

Kerr C (2003) UK launch "virtual" tumour bank to improve treatment research. Lancet Oncol 4:264

Klotz J, Bryant P, Wilcox HB, Dillon M, Wolf B, Fagliano J (2006) Population-based retrieval of newborn dried blood spots for researching paediatric cancer susceptibility genes. Pediatr Perinat Epidemiol 20:449-452

Knoppers BM, Avard D, Cardinal G, Glass KC (2002) Science and society: children and incompetent adults in genetic research: consent and safeguards. Nat Rev Genet 3:221-225

Lévesque E, Fraser W, Knoppers BM (2009) Consent to research: exceptional situations. GenEdit 7(3):1-12

Lyons B (2011) Obliging children. Med Law Rev 19:55-85

McMurter B, Parker L, Fraser RB, Magee JF, Kozancyzn C, Fernandez CV (2011) Parental views on tissue banking in pediatric oncology patients. Pediatr Blood Cancer. doi:10.1002/pbc.22716

Neidich AB, Joseph JW, Ober C, Ross LF (2008) Emprical data about women's attitudes towards a hypothetical pediatric biobank. Am JMed Genet Part A 146:297-304

Organisation for Economic Co-operation and Development (OECD) (2009) Recommendation on Human Biobanks and Genetic Research Databases, Paris

Pembrey M (2004) The avon longitudinal study of parents and children (ALSPAC): a resource for genetic epidemiology. Eur J Endocrinol 151(Suppl 3):U125-U129
Raynor P, Born in Bradford Collaborative Group (2008) Born in Bradford, a cohort study of babies born in Bradford, and their parents: Protocol for the recruitment phase. BMC Public Health 8:327

Ries NM, Legrandeur J, Caulfield T (2010) Handling ethical, legal and social issues in birth cohort studies involving genetic research: responses from studies in six countries. BMC Med Ethics 11:4

Ronningen KS, Paltiel L, Meltzer HM, Nordhagen R, Lie KK, Hovengen R, Haugen M, Nystad W, Magnus P, Hoppin JA (2006) The biobank of the Norwegian Mother and Child Cohort Study: a resource for the next 100 years. Eur J Epidemiol 21:619-625

Rothstein MA (2010) Is deidentification sufficient to protect health privacy in research? Am J Bioeth 10(9):3-11

United Nations Educational, Scientific and Cultural Organization (UNESCO) (2003) International declaration on human genetic data, Paris

Williams G (2011) Children as means and ends in large-scale medical research. Bioethics. doi:10.1111/j.1467-8519.2010.01873.x

Williamson E, Goodenough T, Kent J, Ashcroft R (2004) Children's participation in genetic epidemiology. In: Tutton R, Corrigan $\mathrm{O}$ (eds) Genetic databases: socio-ethical issues in the collection and use of DNA. Routledge, London, pp 139-160

World Health Organization (WHO) (2003) Genetic databases. Assessing the benefits and the impact on human and patient rights, Geneva

World Medical Association (WMA) (2008) Declaration of HelsinkiEthical principles for medical research involving human subjects, Seoul

US Federal Register, 45 C.F.R., part 46 